\title{
ORIGINAL ARTICLE \\ The effect of blood flow restriction and plyometric training methods on dynamic balance of taekwondo athletes
}

\author{
Manolya Akin ${ }^{1 \mathrm{ABCDE}}$, İnci Kesilmiş ${ }^{2 \mathrm{ABCDE}}$ \\ ${ }^{1}$ Mersin University, Mersin, Turkey \\ ${ }^{2}$ Osmaniye Korkut Ata University, Osmaniye, Turkey
}

Authors' Contribution: A - Study design; B - Data collection; C - Statistical analysis; D - Manuscript Preparation; E - Funds Collection

\begin{tabular}{|c|c|}
\hline \multicolumn{2}{|l|}{ Abstract } \\
\hline Purpose: & $\begin{array}{l}\text { Taekwondo (TKD) is a combat sport emphasizing on kicking techniques and dynamic footwork. } \\
\text { Specialized balance ability is crucial for Taekwondo practitioners. Nowadays balance could be improved } \\
\text { with specific strength training such as blood flow restriction and plyometric training. Thus, the aim of this } \\
\text { study was to understand the effect of blood flow restriction (BFR) and pliometric training methods on the } \\
\text { development of dynamic balance at the martial art of Taekwondo. }\end{array}$ \\
\hline Material: & $\begin{array}{l}\text { Totally } 31 \text { TKD athletes between } 15-19 \text { ages participated voluntarily and were divided into three groups } \\
\text { as blood flow restriction }(n=11) \text {, plyometric training }(n=10) \text { and control groups }(n=10) \text {. In addition to } \\
\text { normal taekwondo training, } 8 \text { week training programs were applied to the pliometric and blood flow } \\
\text { restriction groups, and no training program was applied to the control group. At the beginning and } \\
\text { after the trainings, dynamic balance ability measured with Prokin Tecnobody equipment for } 30 \text { seconds } \\
\text { slalom test. }\end{array}$ \\
\hline Results: & $\begin{array}{l}\text { The difference between pre-test and post-test values of BFR group's dynamic balance (antero-posterior } \\
\text { sway) was found to be statistically different }(p<.05) \text { while according to the pliometric training results, } \\
\text { there was no statistically significant difference }(p>.05) \text {. Also, there was not any difference in terms of } \\
\text { gender ( } p>.05) \text {. }\end{array}$ \\
\hline Conclusions: & $\begin{array}{l}\text { Strength development is neccessary for dynamic balance improvement in athletes. Since taekwondo } \\
\text { athletes use strength and balance ability for rapid kicking and change direction, these motor abilities are } \\
\text { important for success. Based on the findings of this study; it is recommended that BFR method may be } \\
\text { useful and so it can be included in training programs. } \\
\text { blood flow restriction. }\end{array}$ \\
\hline & \\
\hline
\end{tabular}

\section{Introduction}

Taekwondo is a sport that requires a combination of many coordinative abilities. Strength, speed, balance, flexibility and coordination, are all important to be able to execute the highly dynamic kicking combinations utilised in taekwondo [1]. Postural control is crucial for taekwondo (TKD) practitioners due to its dynamic kicking nature techniques, in which unilateral stance stability is a determining factor of succes in competititons [2, 3]. The base of support decreases when performing technical strokes on one leg in taekwondo the balance protection become more important than the other biomotor abilities. Somatosensory and vestibular inputs support to maintain dynamic balance in TKD athletes [3, 4]. TKD trainings include high-speed rotations, repetitive actions involving weight-shifting actions and sudden strokes to support the somatosensory and vestibular systems $[5,6]$. Therefore, strength development has significant effects on balance and coordination. The development of strength is not made just for the sake of being strong. On the contrary, the scope of strength development is to serve the specific needs of a given sport, to develop specific strength or its combinations in order to increase athletic performance to the highest possible level [7].

Plyometric training is an effective strength enhancer

(c) Manolya Akin, İnci Kesilmiş, 2020

doi:10.15561/26649837.2020.0401 training method that develops branch-specific biomotor properties (jumps, strokes and direction changes) that require balance, strength and speed [8-10]. Agility is one of the fundamental motoric abilities can be improved by plyometric training movements like starting, stopping and sudden turning. Enhancement agility improves neuromuscular conditioning and strengthening motor functions of muscle fibers through neural adaptation of Golgi tendon organ and joint movement perception skills [11]. Therefore, balance development with plyometric training is a research interest that may be studied.

Another strength training method used in recent years is defined as blood flow restriction or Kaatsu. Popularity of Kaatsu training method is increasing worldwide to improve performance in many athletes [12]. The basic principle of kaatsu is performed by wrapping a restrictive bandage or specially designed pressure belts around the limb while exercising dynamically to restrict the circulation of the working muscle. This bandage is wrapped around the superior point of the extremity where the muscle to be work $[13,14]$. The aim of blood flow restriction (BFR) is to obstruct venous flow without significantly affecting arterial circulation which provides appropriate superficial pressure. When restricting blood flow, the intention is to reduce the amount of arterial flow into the limb and restrict the venous flow out of the 
limb. This type of exercise, when combined with low intensity, promotes muscle hypertrophy and provides various performance improvements [15]. Because of the ischemia that occurs, the body secretes growth hormone as a mechanism of self-protection and thus removes lactic acid and also fat metabolism is activated [13-15]. In recent years, traditional training methods have been applied together with blood flow restriction training [16].

The first two weeks of strength gain are attributed to the functioning of the muscle neuromuscular junction; maintaining balance support the development of strength by providing the neuromuscular junction transmission speed and muscle motor unit participation. Since taekwondo kicks are made from plantar and dorsiflexion, it is thought that the anteroposterior sway of the foot is more effective in taekwondo athletes. So the aim of this study was to understand the effect of plyometric training and blood flow restriction (BFR) methods on the development of dynamic balance at the martial art of Taekwondo.

\section{Material and Methods}

Participants

Research conduct with healty 15-19 years of ages total 31 TKD athletes who were training at the Zirve and Toros Taekwondo Sports Club in Mersin. There were choosen 10 ( 5 male, 5 female) plyometrics, 11 ( 8 male, 3 female) blood flow restriction and 10 (6 male, 4 female) classical taekwondo training group. They had practised TKD for at least two years and attained red belt level or above recruited from two local Mersin TKD associations. The study was approved by the science ethics review by Mersin University Scientific Ethical Committee (2017/03). The procedures were fully explained to the subjects and they all gave their written consents before testing and all procedures of this study were performed in accordance with the Declaration of Helsinki. None of the subjects had any diseases and took any medications. The training program was applied for 6 weeks. They were trained in TKD for two hours per week and they did not have any other physical training. Participants with musculoskeletal disorders, visual, vestibular or neurological disorders affecting balance ability, and any injuries affecting performance in the past six months were excluded.

\section{Dynamic Balance Ability Measurement}

Dynamic balance ability was measured by [Prokin Tecno Body, PKW 200 PL, Italy]. Bipedal dynamic balance measurements were conducted with monoaxial base for antero-posterior sway. Perimeter length (PL) measurement test started when participant provided the balance position with bare foot and thin sportswear. Measurement was conducted twice for each participant for 30 seconds and 60 seconds rest interval was given. Then the researcher recorded the results. For statistical analysis, the more successful dynamic balance score was taken from the three-recorded measurements. In this measurement the participant sees some balls-objectives that come against in the computer software. The participant's scope is to hit the objectives and follow the blue ideal line. At the end of the test the software provides two results: missing objectives and the perimeter length. The perimeter length shows the participants' ability to stay on the blue ideal line. The error is calculated on how much perimeter in more has been store clerk regarding the ideal perimeter (in percentage).

\section{Blood Flow Restriction Protocol}

Both sides of the participants' thighs had pressure applied at the proximal ends by Kaatsu Master belt. This method is similar as previous study protocols (fig. 1) [12, $15,17]$.

\section{Training Program}

All of the Taekwondo trainees were divided into three groups after the pre-test. These three groups participated in the same training program that consist of the same number of strikes and techniques for 6 weeks, 3 days a week and 90 minutes per day. The athletes followed the common warm up period for 30 minutes and delivered 3 stirkes of palding chagi, dollyo chagi and naeryo chagi. In addition to this training; the pliometric training group participated in a 30-minute pliometric exercise program 3 times a week for 6 weeks and the Kaatsu training group participated in a 10 -minute exercise program 3 times a week. After 6 weeks of regular training, post-test measurements were performed in the same protocol for three groups (Fig. 1, Fig. 2).

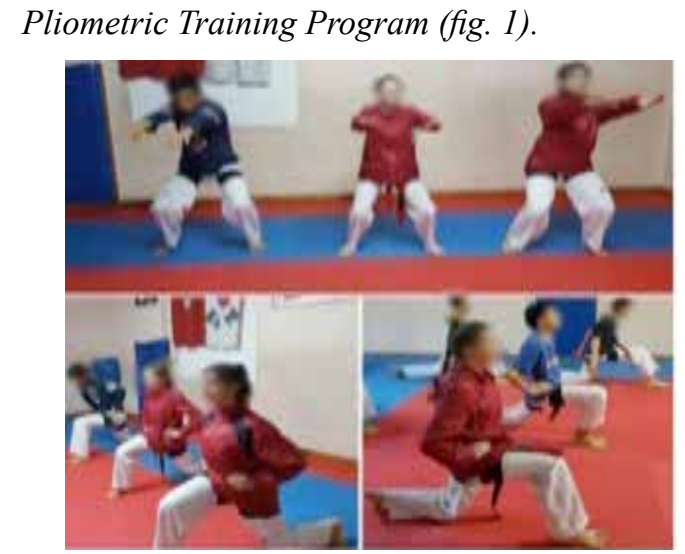

Figure 1. Pliometric Training Program

Plyometric training program consists of; squat jump (The legs are spread over the shoulder width, the back is straight and the knees are slightly bent (Fig. 1). The hips are then lowered until they are parallel to the ground and then jumped up strongly at this point. It falls again after 1 second after falling onto two legs), jump to box (Legs are opened at the width of the hips and the body is leaning towards the box. Half-crouching and jumping into the box without waiting), lateral jump to box (Legs are opened at the width of the hips and the body is standing with the lateral facing towards the box. Half-crouched and jumping into the box without waiting. After landing in the box, take a step back down and move again), bounding with rings (It is descended into the rings arranged on the ground by jumping forward with the right and left feet respectively), box drill with rings (Starting from the half-crouching position, the double legs are jumping on adjacent lined rings, two forward and two rearward. Then 
the one in front of it, the one next to it and the one behind it. The time remaining on the ground is kept as short as possible), lateral hurdle jumps (The legs are opened at the hip width and stand on the side of the box. From the half-crouched position, jump up and sideways to the side of the box and return to the starting position without waiting), split squat jump (Switch to the Lunge position. Jump from here with all the force and change the foot in the air to get back to the lunge position), tuck jump (The legs are shoulder-wide, the knees are slightly bent and then the whole force is jumped up and the knees are pulled to the chest, lateral box push offs (When one foot is on top of the box, use the leg on the ground to jump as much as possible and change feet in the air to descend so that the other foot is on top of the box and the movement is repeated), zig zag hops (Moving over a straight line of about 60 centimeters, bouncing forward and sideways with two feet and jumping left and right), single leg lateral hops (A straight and approximately 60 centimeter line is used to jump forward and sideways with one foot and jump left and right. After the set is finished, jump with the other foot) (Fig. 1).

Blood Flow Restriction Training (fig. 2).
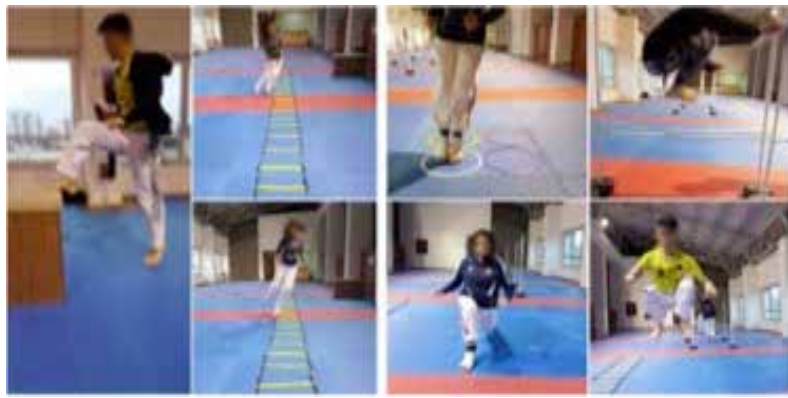

Figure 2. Blood Flow Restriction Trainings
The tire is placed on the proximal part of thigh, and then the athletes performed the movements in 12 repetitions and 3 sets. BFR trainings consist of squat (Participants stand tall with their back straight, feet a little more than hip-width apart and in a straight line about 5-20 degrees. They look straight ahead, keep their back straight. They push the buttocks out, start bending knees and look straight ahead. Then they sit down with their body weight on the heels, hold this pose for 3 seconds and start getting back up), forward lunge (Participants stand tall with feet hip-width apart. They take a big step forward with right leg, start to shift their weight forward so heel hits the floor first. Lower their body until right thigh is parallel to the floor and right shin is vertical. They press into right heel to drive back up to starting position. They repeat the lunge on the other side) and reverse lunge (Participants take a large step backward with the left foot. Lower their hips so that the right thigh (front leg) becomes parallel to the floor with the right knee positioned directly over your ankle. Left knee should be bent at a 90-degree angle and pointing toward the floor with the left heel lifted. They return to standing by pressing the right heel into the floor and bringing left leg forward to complete one repetition (Fig. 2).

\section{Statistical Analysis}

For statistical analysis, firstly normality test was applied and then descriptive statistics and Mann Whitney $\mathrm{U}$ for gender differences. Also, Wilcoxon Signed rank tests were used for training group differences.

\section{Results}

The descriptive statistics of three groups were given in the Table 1. Then, Mann Whitney U test was conducted to compare the pre-test post test gender differences (Table 2 ). According to the results there wasn't any statistically

Table 1. Descriptive Statistics

\begin{tabular}{llllll}
\hline Gender & Groups & & N & Mean & Std. Deviation \\
\hline \multirow{4}{*}{ Pliometric } & PL Pre-test & 5 & 297.58 & 76.20 \\
& & PL Post-test & 5 & 311.06 & 88.95 \\
& & Training Year & 5 & 3.60 & 0.89 \\
Female & BFR & PL Pre-test & 3 & 164.50 & 6.51 \\
& & PL Post-test & 3 & 163.47 & 16.13 \\
& & Training Year & 3 & 6.00 & 3.00 \\
& \multirow{3}{*}{ Control } & PL Pre-test & 4 & 309.78 & 20.29 \\
& & PL Post-test & 4 & 309.38 & 29.05 \\
& & Training Year & 4 & 4.00 & 1.41 \\
& \multirow{4}{*}{ Pliometric } & PL Pre-test & 5 & 329.78 & 56.12 \\
& & PL Post-test & 5 & 315.34 & 36.88 \\
Male & Training Year & 5 & 4.80 & 0.84 \\
& \multirow{3}{*}{ BFR } & PL Pre-test & 8 & 240.53 & 72.68 \\
& & PL Post-test & 8 & 202.14 & 53.61 \\
& & Training Year & 8 & 5.88 & 3.23 \\
& & PL Pre-test & 6 & 233.75 & 65.45 \\
& Control & PL Post-test & 6 & 267.87 & 53.17 \\
& & Training Year & 6 & 4.67 & 2.34 \\
\hline
\end{tabular}

Note. $\mathrm{BFR}=\mathrm{Blood}$ Flow Restriction, $\mathrm{PL}=$ Perimeter Length 
significant difference in terms of gender ( $p>.05)$.

The Wilcoxon Signed Rank test evaluated for three groups to show pre-test, post-test perimeter length difference (Table 3). There was statistically significant difference on dynamic balance ability in blood flow restriction groups $(\mathrm{p}<.05)$. Perimeter Length scores for the female blood flow restriction group is $163.47 \pm 16.13$, whereas it is $202.14 \pm 53.61$ for the males. This difference indicate that female participants have better dynamic balance results. There wasn't any difference in dynamic balance of plyometric training and control group pre-post test results (Table 3, fig. 3).

The mean values according to gender and research groups were given in Table 1. Female participants had better PL Post test mean values than male participants except control group (Table 1.). There was any statistically significant difference in Pre-Post test results for dynamic balance variable according to gender (Table 2). The BFR group post-test PL difference was statistically significant (Table 3). There weren't any statistically significant difference in plyometric and control groups according to Wilcoxon Signed Rank Test results.

\section{Discussion}

It is important that using effective dorsiflexion and plantar flexion in dollyo chagi and yopchagi techniques that the strength and balance ability work together. Therefore, different training methods that can improve antero-posterior sway are important for Taekwondo athletes. In this study, the difference between pre-test

Table 2. Dynamic Balance Ability According to Gender

\begin{tabular}{lllll}
\hline PL & Mann-Whitney U & Wilcoxon W & Z & Asymp. Sig. (2-tailed) \\
\hline PL Pre-test & 111 & 301 & -0.12 & 0.90 \\
PL Post-test & 96 & 286 & -0.73 & 0.47 \\
\hline
\end{tabular}

Note. PL=Perimeter Length

Table 3. Dynamic Balance According to Training Groups

\begin{tabular}{|c|c|c|c|c|c|c|}
\hline Gruplar & & $\mathbf{n}$ & $\bar{x}_{\text {sira }}$ & $\sum_{s i r a}$ & $\mathbf{Z}$ & $\mathbf{p}$ \\
\hline \multirow{3}{*}{$\begin{array}{l}\text { Pliometric Group } \\
\text { Pre Test-Post Test }\end{array}$} & Negative Rank & $5^{a}$ & 5.6 & 28 & \multirow{4}{*}{$-.051^{a}$} & \multirow{4}{*}{,959 } \\
\hline & Positive Rank & $5^{b}$ & 5.4 & 27 & & \\
\hline & Equal & $0^{c}$ & & & & \\
\hline $\mathrm{PL}$ & Total & 17 & & & & \\
\hline BER Groun & Negative Rank & $10^{\mathrm{a}}$ & 6 & 60 & \multirow{4}{*}{$-2.401^{\mathrm{a}}$} & \multirow{4}{*}{,016* } \\
\hline Dre tos & Positive Rank & $1^{b}$ & 6 & 6 & & \\
\hline \multirow{2}{*}{$\mathrm{PL}$} & Equal & $0^{c}$ & & & & \\
\hline & Total & 15 & & & & \\
\hline Control Group & Negative Rank & $3^{a}$ & 5.67 & 17 & \multirow{4}{*}{$-1.070^{b}$} & \multirow{4}{*}{ 285 } \\
\hline Pre Test-Pest Test & Positive Rank & $7^{\mathrm{b}}$ & 5.43 & 38 & & \\
\hline \multirow{2}{*}{ PL } & Equal & $0^{c}$ & & & & \\
\hline & Total & 10 & & & & \\
\hline
\end{tabular}

a $\mathrm{pl} 2<\mathrm{pl} 1 ; \mathrm{b}$ pl2 $>\mathrm{pl} 1 ; \mathrm{c}$ pl2 = pl1

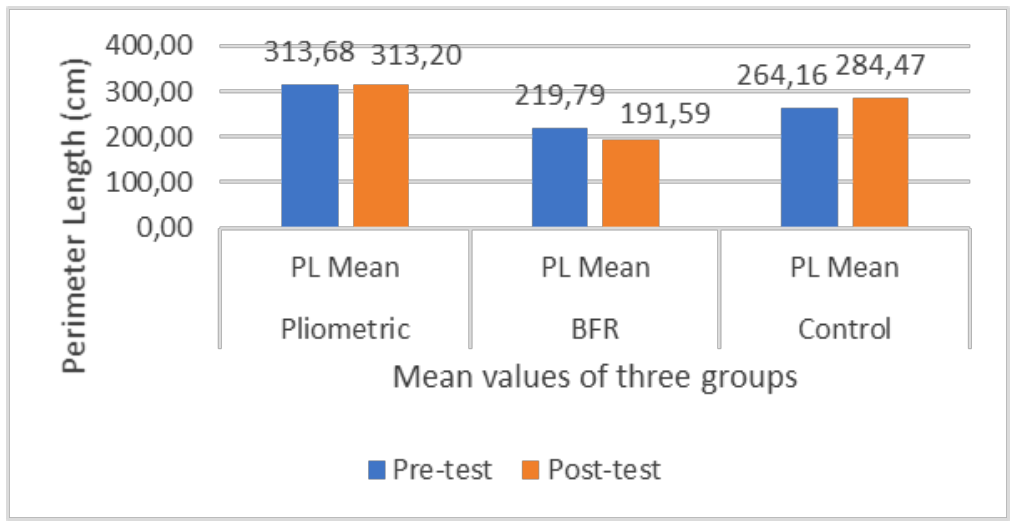

Figure 3. Pre-test Post-test Perimeter Length Differences 
and post-test values of BFR group's dynamic balance was found to be statistically different (Table 3, Fig.3). No gender differentiation was observed (Table 1, Table 2). There are studies that support BFR training effect on increasing the amount of circulating growth hormone [12, $14,18]$. This may enhance lipolysis and bone formation, resulting in improving strength and inducing hypertrophy of muscle [19]. Abe et.al. reported that skeletal muscle hypertrophy and strength gain occurred even after two weeks of LIT-Kaatsu training. It also produced increases in skeletal muscle size $(7-8 \%)$ that were similar in magnitude to traditional training of 3-4 months [20]. Similarly, eyes open and closed balance performance was better than peers in taekwondo players who participate low level 4 hours per week TKD training [3]. There are studies reporting that BFR improves strengthThe first two weeks of strength gain are associated with neuromuscular muscle conduction. Therefore, it is assumed that force development has an effect on balance development. Luebbers et al. reported that strength gain was higher in Kaatsu group and blood flow restriction bands on the knees are recommended to trainers [21].

In this study we measured dynamic balance ability for antero-posterior sway and there was no statistically significant difference on dynamic balance ability after plyometric training program (Table 3.). Similar to this study Benis et al. observed that national female basketball players enhanced their scores on the $\mathrm{Y}$ balance test in both postero-medial and postero-lateral but not in the anterior plane following 8 weeks of biweekly bodyweight neuromuscular training [22]. But in contrast to this study Cherni et al. reported significant improvement in the ability of static and dynamic postural control after 8 week plyometric training program [23]. Also, Myer et al. reported that after 7 week of plyometric training high school female volleyball players decreased their medio- lateral center of pressure, despite the absence of change in the antero-posterior center of pressure [24].

Taekwondo athletes use strength and balance ability for rapid kicking and change direction, these motor abilities are important for success. As a conclusion, based on the research findings; it is recommended that BFR method can be useful and useable in taekwondo training programs.

\section{Conclusions}

Important and necessary strength in body balance required in taekwondo is practiced with different techniques in the literature. The first two weeks of strength gain is affected by neuromuscular muscle harmony. Therefore, the balance development that occurs in the strength training is important. Traditional strength exercise involves training with $80 \%$ of a repetitive maximal force. Therefore, a long time is required in the training period. However, Plyometric and BFR workouts are applied for a short time with lower intensity rates. Plyometric training method, on the other hand, contributes to the explosive strength gain. BFR method can be applied for only 10 minutes. In this study, the BFR training performed with a $20 \%$ intensity force that was not used before in the taekwondo and the balance gains in traditional plyometric training were investigated. As a result, bfr training with low intensity positively affected the dynamic balance. In our study, balance development was observed as a result of plyometric training, but it was not statistically significant. Therefore, bfr trainings are recommended in taekwondo branch in order to ensure dynamic balance development as well as strength enhancement.

\section{Conflicts of Interest}

The authors state no conflicts of interest.

\section{References}

1. Lystad RP, Pollard H, Graham PL. Epidemiology of injuries in competition taekwondo: A metaanalysis of observational studies. Journal of Science and Medicine in Sport. 2009; 12(6): 614-621. https://doi.org/10.1016/j.jsams.2008.09.013

2. Taekwondo PW. In: Kordi R, Maffulli N, Wroble RR, editors. Combat sports medicine. [chapter 15] London: Springer Science; 2009.

3. Leong HT, Fu SN, Ng GY, Tsang WW. Low-level Taekwondo practitioners have better somatosensory organisation in standing balance than sedentary people. European journal of applied physiology. 2011; 111(8): 1787-1793. https://doi.org/10.1007/s00421-010-1798-7

4. Jagiello W. Differentiation of the body composition in taekwondo-ITF competitors of the men's Polish national team and direct based athletes. Archives of Budo. 2015;11:329338.

5. Fong $\mathrm{SS}, \mathrm{Fu} \mathrm{SN}, \mathrm{Ng}$ GY. Taekwondo training speeds up the development of balance and sensory functions in young adolescents. Journal of Science and Medicine in Sport. 2012; 15(1): 64-68. https://doi.org/10.1016/j.jsams.2011.06.001
6. Kalina RM, Jagiello W, Barczynski BJ. The method to evaluate the body balance disturbation tolerance skills-validation procedure of the 'Rotational Test'. Archives of Budo. 2013;9(1):59-80. https://doi.org/10.12659/aob.889208

7. Bompa TO. Sporda çabuk kuvvet antrenmanı [Quick strength training in sports]. Ankara: Bağırgan Yayımevi; 2001. (In Turkish)

8. Foran B. High Performance Sports Conditioning. Human Kinetics; 2001.

9. Matavulj D, Kukolj M, Ugarkovic D, Tihanyi J, Jaric S. Effects of plyometric training on jumping performance in junior basketball players. Journal of Sports Medicine and Physical Fitness. 2001; 2: 41-45.

10.Reyment CM, Bonis ME, Lundquist JC, Tice BS. Effects of a four week plyometric training program on measurements of power in male collegiate hockey players. J. Undergrad. Kin. Res. 2006; 1(2): 44-62.

11.Atacan B. Effect of an 8-week specially arranged plyometric training on the power and agility of young male soccer players. [Master Thesis]. Kırıkkale University, Health Sciences Institute, Department of Physical Education and Sports, Kirıkkale; 2010. 
12.Takarada Y, Nakamura Y, Aruga S, Onda T, Miyazaki S, Ishii N. Rapid increase in plasma growth hormone after lowintensity resistance exercise with vascular occlusion. Journal of Applied Physiology. 2000 [cited 2000; 88(1): 61-65. https://doi.org/10.1152/jappl.2000.88.1.61

13.Fujita T, Brechue WF, Kurita K, Sato Y, Abe T. Increased muscle volume and strength following six days of lowintensity resistance training with restricted muscle blood flow. Int $J$ KAATSU Train Res. 2008; 4: 1-8. https://doi.org/10.3806/ijktr.4.1

14. SatoY.ThehistoryandfutureofKAATSUtraining. International Journal of KAATSU Training Research, 2005; 1(1): 1-5. https://doi.org/10.3806/ijktr.1.1

15.Abe T, Kearns CF, Sato Y. Muscle size and strength are increased following walk training with restricted venous blood flow from the leg muscle, KAATSUwalk training. $J$ Appl Physiol, 2006; 100: 1460-1466. https://doi.org/10.1152/japplphysiol.01267.2005

16.Luebbers PE, Witte EV, Oshel JQ, Butler MS. Effects of practical blood flow restriction training on adolescent lower-body strength. The Journal of Strength \& Conditioning Research, 2019; 33(10): 2674-2683. doi: 10.1519/JSC.0000000000002302

17.Nakajima T, Takano H, Kurano M, Iida H, Kubota $\mathrm{N}$, Yasuda $\mathrm{T}$. et al. Effects of KAATSU training on haemostasis in healthy subjects. International Journal of KAATSU Training Research, 2007; 3(1): 11-20. https://doi.org/10.3806/ijktr.3.11

18. Takano T, Ohe Y, Sakamoto H, Tsuta K, Matsuno Y, Tateishi U. et al. Epidermal growth factor receptor gene mutations and increased copy numbers predict gefitinib sensitivity in patients with recurrent non-small-cell lung cancer.
Journal of Clinical Oncology, 2005; 23(28): 6829-6837. https://doi.org/10.1200/JCO.2005.01.0793

19.Beekly MD, Sato Y, Abe T. KAATSU-walk training increases serum bone-spesific alkaline phosphatase in young men. Int. J. KAATSU Training Res, 2005; 1:77-81. https://doi.org/10.3806/ijktr.1.77

20.Abe T, Yasuda T, Midorikawa T, Sato Y, Inoue K, Koizumi K, Ishii N. Skeletal muscle size and circulating IGF-1 are increased after two weeks of twice daily "KAATSU" resistance training. International Journal of KAATSU Training Research, 2005; 1(1): 6-12. https://doi.org/10.3806/ijktr.1.6

21.Luebbers PE, Fry AC, Kriley LM, Butler MS. The effects of a 7-week practical blood flow restriction program on well-trained collegiate athletes. The Journal of Strength \& Conditioning Research, 2014; 28(8): 2270-2280. https://doi.org/10.1519/JSC.0000000000000385

22.Benis R, Bonato M, Torre AL. Elite female basketball players' body-weight neuromuscular training and performance on the Y-balance test. Journal of athletic training, 2016; 51(9): 688-695. https://doi.org/10.4085/1062-6050-51.12.03

23.Cherni Y, Jelid MC, Mehrez H, Shephard RJ, Paillard TP, Chelly MS, Hermassi S. Eight weeks of plyometric training improves ability to change direction and dynamic postural control in female basketball players. Frontiers in Physiology, 2019; 10: 726. https://doi.org/10.3389/fphys.2019.00726

24.Myer GD, Ford KR, McLea SG, Hewett TE. The effects of plyometric versus dynamic stabilization and balance training on lower extremity biomechanics. The American journal of sports medicine, 2006; 34(3): 445-455. https://doi.org/10.1177/0363546505281241

\section{Information about the authors:}

Manolya Akin; Assoc. Prof.; https://orcid.org/0000-0002-2101-073X; manolya66@gmail.com; Faculty of Sport Sciences, Department of Physical Education and Sports, Mersin University; Mersin 33343, Mersin, Turkey.

İnci Kesilmiş; (Corresponding Author); Assist. Prof.; https://orcid.org/0000-0002-2382-2205; incikesilmis@osmaniye.edu.tr; School of Physical Education and Sports, Osmaniye Korkut Ata University; Osmaniye, Turkey.

Cite this article as:

Manolya Akin, İnci Kesilmiş. The effect of blood flow restriction and plyometric training methods on dynamic balance of Taekwondo athletes. Pedagogy of physical culture and sports, 2020;24(4):157-162. https://doi.org/10.15561/26649837.2020.0401

This is an Open Access article distributed under the terms of the Creative Commons Attribution License, which permits unrestricted use, distribution, and reproduction in any medium, provided the original work is properly cited (http://creativecommons.org/licenses/by/4.0/deed.en).

Received: 17.12.2019

Accepted: 12.01.2020; Published: 30.08.2020 